\title{
Complementarities between Innovation Policies in Emerging Economies. The case of Argentina's software sector.
}

\author{
MOTTA, Jorge José \\ Instituto de Economía y Finanzas, \\ Facultad de Ciencias Económicas, \\ Universidad Nacional de Córdoba. \\ Calle Valparaíso S/N, Ciudad Universitaria, Córdoba, Argentina. \\ E-mail: jimotta@eco.unc.edu.ar
}

\author{
MORERO, Hernán Alejandro * \\ Universidad Nacional de Córdoba. \\ Rondeau 467, $1^{\circ}$ Piso, Córdoba, Argentina. \\ Facultad de Ciencias Económicas, \\ Universidad Nacional de Córdoba. \\ Calle Valparaíso S/N, Ciudad Universitaria, Córdoba, Argentina. \\ E-mail: hernanmorero@eco.uncor.edu
}

Centro de Investigaciones y Estudios sobre Cultura y Sociedad (CIECS) - CONICET,

\section{BORRASTERO, Carina}

Consejo Nacional de Investigaciones Científicas y Técnicas (CONICET)

Argentina.

Instituto de Altos Estudios Sociales, Universidad Nacional de San Martín.

Calle Valparaíso S/N, Ciudad Universitaria, Córdoba, Argentina.

E-mail: carinaborrastero@ conicet.gov.ar

\section{ORTIZ, Pablo Arnaldo}

Facultad de Ciencias Económicas,

Universidad Nacional de Córdoba.

Calle Valparaíso S/N, Ciudad Universitaria, Córdoba, Argentina.

E-mail: portiz@eco.unc.edu.ar

\begin{abstract}
This paper analyses the presence of complementarity and substitutability relations between innovation policies in the software sector from Argentina. Supermodularity and submodularity tests between obstacles to innovation were performed with technological data from 257 Argentinean software firms, for the period 2008-2010. This research adds empirical evidence on the complementarities and supplementarities of innovation policies in an emerging economy and in a Knowledge Intensive Business Services sector. This kind of analysis allows to evaluate the convenience to attack jointly or separately a set of obstacles or separately. The results show multiple feedback relations between diverse obstacles and consequently between policies, and the main finding is that, in this emerging economy, innovation policies aimed to encourage firms to become innovators serve as well as an incentive for innovative firms to increase and intensify its innovation performance.
\end{abstract}

Keywords: Knowledge Intensive Business Services; Software Sector; Argentina; Supermodularity; Innovation Policy.

\section{Biographical Notes:}

Jorge José Motta obtained his $\mathrm{PhD}$ in Business Creation, Development and Management from the Universitat Autònoma de Barcelona, Spain, and his MSc in Economics from the Universidade Estadual de Campinas, Brazil. He is Full Professor and Researcher at the Universidad Nacional de Córdoba, Argentina and an active member of the Mercosur SMEs Network. His research interests relate to technology, innovation and development, with 
particular attention to firm-level capability building, learning, creativity and innovation. $\mathrm{He}$ has published several articles and book chapters on these topics.

Hernán Alejandro Morero is Ph.D. on Economics and a postdoctoral researcher on the Center of Studies on Culture and Society (Centro de Investigaciones y Estudios sobre Cultura y Sociedad-CIECS) from CONICET (National Scientific and Technical Research Council from Argentina), under the research project Complementarities of Innovative Activities in Knowledge Intensive Business Services: The case of the argentinean Software and IT Services Production Sector. He is also an Assistant Professor of Industrial Economics and History of Economic Thought in the Faculty of Economics from Universidad Nacional de Córdoba. His research interests include innovation and learning processes at firm-level in diverse industries and technological strategies for developing economies. He has published diverse articles related to industrial and innovation economics, as well related to history of economic thought.

Carina Borrastero is a Master degree in Science, Technology and Society, graduate at National University of Quilmes. She is also a Doctoral fellow at National Scientific and Technical Research Council from Argentina based in Institute of High Social Studies, currently doing his $\mathrm{PhD}$ at Faculty of Social Sciences, University of Buenos Aires. Her current research project is entitled State, Entrepreneurs and Economic Development. Government Intervention and Corporate Action in developing the Software and IT Services Sector from Córdoba. 2000-2012. She has published diverse articles about state action, public policies, development and innovation in software sector.

Pablo Arnaldo Ortiz has a degree on Economics at Faculty of Economics, National University of Córdoba. He is currently doing his Master of Applied Statistics at Faculty of Economics, and participating in the research project entitled "Study of the Sticky Behavior of Costs in Argentine Companies listed on the Stock Exchange". He is also Assistant Professor of Statistics, Multivariate Analysis and Mathematical Analysis in the Faculty of Economics from Universidad Nacional de Córdoba.

\section{INTRODUCTION}

As innovation process of the firms is constrained by diverse barriers, governments try to stimulate the growth and consolidation of strategic sectors through innovation policies with the objective to neutralize the obstacles to innovation or, diminish their constraining effects. Assuming a monotone inverse relation between obstacles and innovation policies, it is possible to evaluate complementarities between policies through the data on obstacles. Following a rigorous and previously accepted method developed by Mohnen and Röller (2005) the paper will analyse the presence of complementarities and supplementarities between innovation policies in the software production sector in Argentina.

The available empirical literature that applies this technique is scarce, especially for emerging economies, where a notable gap in the literature can be detected. On the other hand, the empirical studies have been focused on manufacturing sectors. Thus, the main contribution of the paper is twofold: to highlight the existence of complementarities and supplementarities of innovation policies in an emerging economy, and in a particular Knowledge Intensive Business Services (KIBS) sector, the software production.

Besides the global leaders of the software sector have remained in the developed world, over the 1990s many developing countries, especially from Asia, have catch up and gained a competitive position among the main global actors (Malerba and Nelson, 2011, Niosi et al., 
2012) ${ }^{1}$. Brazil and Argentina, following the Asian model, have recognized the importance of intangible goods - for their potential of direct economic impact.

In Argentina, the software sector is composed of around 1600 companies with five or more employees (Barletta et al., 2013), who occupy about 80,000 workers. This activity has shown a high dynamism. Between 2003 and 2012 employment, sales and exports have grown at an annual average rate of $17 \%, 16.6 \%$ and $18.6 \%$, respectively (OPSSI, 2013). Among the reasons for this strong growth it should be noted a set of public policies aimed at promoting quality certification, export activity, the formation of qualified human resources, infrastructure development and innovative activity. These policies include the Software Act (2004), the Trust Fund for the Promotion of the Software Industry (FONSOFT), the promotion of careers in computer science, etc. The interest of the article lies on some aspects of public policies for the promotion of innovation in the sector. In spite of the significant effort performed by the Argentine Government to foster innovation, the funds allocated for this purpose are limited, so that there is implicitly a competition for funds between different policies.

As the attenuation of an obstacle can diminish the negative effects of a complementary obstacle, it reinforces the reasons to consider less likely to remove both at the same time, meaning that policies are supplementary. Thus, the issue if the policies are complementary or supplementary is not trivial and has implications to the efficiency in the innovation policy design. In that sense, the paper also contributes with practical implications arising from the complementarities existent between obstacles.

This paper is organized as follows. Section 2 presents our empirical and theoretical background, focused on innovation studies on services, KIBS and the Software Sector and the literature about obstacles to innovation and policy complementarities. Section 3 presents our research design and methods, focused on econometric issues and complementarity tests, and the data source and indicators used. In section 4 we present our main empirical findings and offer some implications for policy makers. Section 5 presents our conclusions and final remarks.

\section{EMPIRICAL AND THEORETICAL BACKGROUND}

\subsection{Innovation Studies on Services, KIBS and the Software Sector}

From late nineties diverse authors worked on a demarcation vision between innovation on services respect from manufacturing sectors (Djellal and Gallouj, 2001, Gallouj and Weinstein, 1997). Innovation studies on services pointed out that there are particular aspects in the nature of the services production itself which distinguishes their innovation process respect to the manufacturing industry (Drejer, 2004, Gallouj and Savona, 2009, Miles, 2004): inmateriality, continuous reconfiguration of supply, coproduction, simultaneity of provision and consumption (Gallouj and Savona, 2009).

In recent decades, there has been an increasing interest on a special kind of services: the KIBS. These intensive knowledge services are characterized by concentrate its production on providing intangible inputs to knowledge-intensive business processes in other organizations, both public and private, and by heavily depending on specialized knowledge and typically, such firms have high levels of qualified staff (Muller and Doloreux, 2009, Miles, 2005, Miles et al., 1995). Some kind of KIBS is based on legal, administrative or commercial knowledge,

1 - This, has motivated a number of scholars to investigate the sector on emerging economies, as Arora et al (2001), Athreye (2005), Chudnovsky and Lopez (2005), Rizk (2012), Uriona et al. (2013), Hajela and Akbar (2013), as many others 
while others rely particularly on scientific and technological knowledge. The last kind of KIBS sectors are among the most active innovators in developed economies, according to various reports based on technological surveys (Tether and Swan, 2003). Within the KIBS sectors, the software and related IT services sector is one of the most innovative in developed economies and in some catching-up economies as well (Tether and Swan, 2003, Niosi et al., 2012). As well a part of the literature has been interested on addressing public policy and KIBS (Miles, 2005), there are also in the innovation studies of the software sector an important group focused on policy making and its structural characteristics at the national level or in product segments (Anchordoguy, 2000, Arora et al., 2001, Breznitz, 2007, Mowery and Langlois, 1996).

This paper is partially related to this group because it aims to contribute to innovation policy making in the software sector in an emerging economy, focusing on the complementarities that could arise between policy innovation actions in this sector.

\subsection{Obstacles to innovation and policy complementarities}

There is an important empirical literature which analyzes the role of obstacles to innovation (D'Este et al., 2012) ${ }^{2}$. A first line of research focuses on the factors affecting the perception of the importance of the barriers (Galia and Legros, 2004, Iammarino et al., 2009). A second line focuses on the impact of the obstacles on the intensity of innovation and/or the propensity to innovate (Mohnen and Röller, 2005, Savignac, 2008, Tourigny and Le, 2004, MadridGuijarro et al., 2009, Strube and Resende, 2009, D'Este et al., 2012). In this line, some studies investigate the impact of obstacles to innovation on the propensity to innovate and/or the intensity of the innovativeness of firms, either on innovation inputs, or innovation outputs (D'Este et al., 2012, Madrid-Guijarro et al., 2009, Mancusi and Vezzulli, 2010, Savignac, 2008). These studies point out that there is an endogeneity of the perception of obstacles, and the innovativeness degree of the firms ${ }^{3}$. Another group, analyzes the relation between obstacles and innovation output of the firms, assuming obstacles as failures, insufficiencies or lack of public policy (Mohnen and Röller, 2005, Strube and Resende, 2009). We will follow this last perspective, and will be concerned on what kind of complementarities or supplementarities could arise between obstacles to innovation, related directly with the innovation output of firms, resorting to an innovation survey data source.

Innovation surveys, based on the innovation studies, have typically been concentrated in four kinds of obstacles to innovation:

-Financial and risk obstacles to innovation, addressing lack of appropriate sources of finance or formal restrictions to financial access; when the innovation costs seem to be very high or the pay-off period for the innovations is too long; when the interest rates are too high or the perceived risk seems to be excessive.

- Internal knowledge-skills obstacles, when there is a lack of skilled human resources or it is too difficult to keep the more qualified personnel in the firm; when there is an internal lack of information on technologies or markets; when the costs of innovation are very hard to control, the capabilities of the firm offer a small innovation potential; or when there is a resistance to change in the organizational structure of the firm.

- Appropriability obstacles; when the innovations in the sector are too easy to copy there is a lack of established appropriate property rights or a weak enforcement of norms; or when the

\footnotetext{
${ }^{2}$ A revision and a systematization of the literature regarding barriers to innovation also could be consulted in Madrid-Guijarro (2009).

${ }^{3}$ That motivates D'Este (2012) to distinguish between perceived barriers to innovation in a discouraging or a deterring manner, from revealed barriers to innovation, when firms already done certain level of innovative activities of different kinds.
} 
appropriability mechanisms are too expensive, difficult or ineffective to protect the economic benefits of innovation.

- External knowledge-skills obstacles, when there are deficiencies in the availability or quality of external technical services; when there is a lack of technological or innovation opportunities in the market, the uncertainty of the demand is too high, there are scarce opportunities for cooperation with other firms or institutions or the institutional R\&D network is very weak; or when there is no need to innovate due to earlier innovations.

These obstacles could appear jointly or separately, and could be more important in some instances of the innovation process than in others. The policy could be focused on jointly or separately removing a group of obstacles. That's why it is important to analyze the complementarities that could arise between diverse innovation policies.

The framework developed by Mohnen and Röller (2005) allows to identify complementarities in innovation policies using discrete data through the innovation function ${ }^{4}$. It is assumed that innovation in a firm is characterized by an innovation function $I_{i}(a, \beta)$, where the government could choose a set $J$ of policy variables denoted by $a=\left(a_{1}, a_{2}, \ldots, a_{J}\right)$, and there is a set $\beta$ of other firm-specific factors affecting innovation: competences, linkages and innovative efforts as long structural aspects, size, property of capital, etc.

Complementarities could be directly tested asking if the innovation function is supermodular in $a$ (see follow). Unfortunately, the available data on innovation, particularly from innovation surveys, do not usually offer exhaustive data about government promoting mechanisms to benefit firms and innovation performance. Instead, data concerning the obstacles to innovation are usually available. Thus, assuming a monotone inverse relation between obstacles and policy actions, it is possible to evaluate complementarities between policies, through the data on obstacles (Mohnen and Röller, 2005). Defining the obstacles as $C=-a$, we can identify complementarities between policies, testing if $I(C, \beta)$ is submodular in $C$.

Testing for complementarities between two variables when the nature of the available data regarding the key variables is discrete, implies testing if the objective function is supermodular in these arguments ${ }^{5}$. Supermodular functions belong to a mathematical field known as Lattice Theory ${ }^{6}$. A real function $I(x)$ defined in the lattice $X$ is supermodular in $x$ if $I\left(x^{\prime}\right)+I\left(x^{\prime \prime}\right) \leq I\left(x^{\prime} \vee x^{\prime \prime}\right)+I\left(x^{\prime} \wedge x^{\prime \prime}\right)$ is satisfied by all $x^{\prime}$ and $x^{\prime \prime}$ in $X$. When the inequality is inverse, $I(x)$ is submodular. The condition of supermodularity between two arguments implies that the function shows complementarity between these arguments, and the condition of submodularity shows substitutability (Milgrom and Roberts, 1990, Topkis, 1998).

Assuming that innovation function depends, in addition to traditional explanatory factors, on the presence of obstacles to innovation, testing for the complementarities (substitutabilities) in innovation obstacles has particular policy implications.

Following Mohnen and Röller (2005), if two obstacles are substitutes, the presence of one obstacle moderates the negative effects on innovation of the other. In that case, removing one

\footnotetext{
${ }^{4}$ This is a "direct objective function approach", as long it evaluates the complementarities in direct relation to innovation. Another alternative used to be the "correlation approach", computing simple correlations, entailing or not controls for other aspects, observed or not observed (Mohnen and Röller, 2005).

${ }^{5}$ When continuous data about independent variables are available, an alternative in the "direct objective function approach" is to regress the innovation variable with a cross variable of the dependent variables that we want to test their complementarity, besides the controls. Examples of this exercise in innovation economics are Lokhin et al. (2008) and Hou and Mohnen (2011).

${ }^{6} \mathrm{~A}$ Lattice is a partially ordered set, where there is a binary relation that is reflexive, anti-symmetric and transitive; and where for each pair of elements there is a supremum by pairs $\left(x^{\prime} \vee x^{\prime \prime}\right.$, the join) and a infimum ( $x^{\prime} \wedge x^{\prime \prime}$, the meet), that are contained inside the set (Milgrom and Roberts, 1990, Topkins, 1998).
} 
obstacle or diminishing its negative impacts on innovation, will exacerbate the negative effects of the other. That is why it is convenient to engage both obstacles jointly, and because it could be said that the policy actions are complementary. Submodularity in innovation obstacles means supermodularity in innovation policy actions. In the same way, if two obstacles are complementary, the obstacles reinforce each other. Removing one or diminishing the negative effects on innovation of one of them, will attenuate the other one. In this case, there are less arguments to remove both simultaneously, and the supermodularity in innovation obstacles means submodularity in innovation policy actions.

In Innovation Economics, two important works that applied supermodularity tests to data about European firms were Miravete and Pernias (2006), that analyzed complementarities between product and process innovation, and Cassiman and Veugelers (2006), that analyzed the complementarity between in-house $R \& D$ activities and the external purchase of technology. Mohnen and Röller (2005) applied this methodology to test the complementarity relations between obstacles to innovation in European manufacturing firms during the nineties. They distinguished two phases of the innovation process in firms: the phase of the decision to innovate or not, and the phase of how much to innovate. In these two phases, they tested the complementarities between four obstacles to innovation: legislation and norms, lack of cooperation opportunities, lack of skilled personnel and lack of appropriate sources of finance. Their findings point out that the complementarities between obstacles differ regarding the phase of the innovation process of the firm.

It seems a promising path to get useful insights to evaluate and to design sectoral innovation policies, particularly to the economies behind the international technological frontier. However, the main findings are only concentrated in developed countries and the studies in emergent economies are incipient or inconclusive ${ }^{7}$. On the other hand, in general, there are no studies focused on the services sector, even less in KIBS sectors. The objective of the paper is to contribute to fill these gaps in the literature, evaluating the complementarities between policy innovation actions in a KIBS sector from an emerging economy: Argentina's software firms.

\section{RESEARCH DESIGN AND METHODS}

\subsection{Econometric Issues and Complementarity Tests}

To test the complementarity inequalities and to estimate the coefficients of the obstacles to innovations, an innovation function for each firm $i$ is specified in [1], where $I$ represents the intensity of innovation.

$$
I_{i}=\sum_{l=0}^{2^{k}-1} \gamma_{l} s_{i l}+\sum_{j=1}^{p} \beta X_{i j}+\varepsilon_{i}
$$

On the other hand, $s_{i l}$ represents a dummy related to the obstacle state $l$. Taking into account that there are $2^{k}-1$ possible states, 16 dummies are defined $(\mathrm{k}=2)$. The coefficients of these dummies $\left(\gamma_{l i}\right)$, will be necessary to carry out the complementarity tests.

\footnotetext{
${ }^{7}$ A particular CESIfo working paper should be pointed out. Strube and Resende (2009) tested complementarities between obstacles to innovation (lack of information on technology or on market, lack of cooperation opportunities, lack of skilled personnel and lack of finance sources), using data from PINTEC-2003, for Brazilian manufacturing firms. Their preliminary results showed some particular complementarities in the stage of begin to innovate (between lack of information and skilled personnel, and lack of information and cooperation opportunities), and complementarities between all the obstacles, token by pairs, in order to improve the level of innovation. In that stage, also some substitutability between obstacles was found simultaneously.
} 
Additionally, control variables are included, represented by $X_{i}$ : the main determinants of innovation, as competences, linkages and innovative efforts, and the firm's structural aspects (size, origin of capital and exports).

We will test the complementarity of each pair of obstacles separately. This contrast implies that for each comparison, one must conjunctively test a system of four equations. With an innovation function defined by [1] and the states of dummy variables, it is possible to define the following series of inequalities for each pair of obstacles:

$\begin{array}{llll}\text { Comp. (1-2) } & \gamma_{8+s}+\gamma_{4+s} \leq \gamma_{0+s}+\gamma_{12+s}, & \text { where } s=0,1,2,3 \\ \text { Comp. (1-3) } & \gamma_{8+s}+\gamma_{4+s} \leq \gamma_{0+s}+\gamma_{1+s}, & \text { where } s=0,1,4,5 \\ \text { Comp. (1-4) } & \gamma_{8+s}+\gamma_{2+s} \leq \gamma_{0+s}+\gamma_{9+s}, & \text { where } s=0,2,4,6 \\ \text { Comp. (2-3) } & \gamma_{4+s}+\gamma_{2+s} \leq \gamma_{0+s}+\gamma_{6+s}, & \text { where } s=0,1,8,9 \\ \text { Comp. (2-4) } & \gamma_{4+s}+\gamma_{1+s} \leq \gamma_{0+s}+\gamma_{5+s}, & \text { where } s=0,2,8,10 \\ \text { Comp. (3-4) } & \gamma_{2+s}+\gamma_{1+s} \leq \gamma_{0+s}+\gamma_{3+s}, & \text { where } s=0,4,8,12\end{array}$

Moreover, as mentioned, the innovation function could be submodular, meaning that the obstacles are substitutes. The system of inequations to be tested would be analogous to the previous ones, but the inequality would be presented in opposite signs.

The possibility to carry forward hypothesis tests around super- and submodularity will be feasible if the estimates are consistently counted in $\gamma_{l}$ `s. With these estimations, it will be possible to state the hypothesis for the comparison. For example, to compare the complementarity between the obstacles 1 and 2, the following hypothesis would be defined:

$H_{0}: h_{0} \leq 0$ and $h_{1} \leq 0$ and $h_{2} \leq 0$ and $h_{3} \leq 0$

$H_{1}: h_{0}>0$ or $h_{1}>0$ or $h_{2}>0$ or $h_{3}>0$

Where $h_{s}=-\gamma_{0+s}+\gamma_{8+s}+\gamma_{4+s}-\gamma_{12+s}$ and $s=0,1,2,3$. Two important aspects should be taken into account. First, to reject $H_{0}$ does not imply that the two obstacles in question are substitutes. Second, $H_{1}$ implies that the inequations formed can have distinct signs. In this situation, complementarity nor substitutability do not exist.

The argument for the approach of the hypothesis in order to test if the existence of submodularity is analogous:

$H_{0}: h_{0} \geq 0$ and $h_{1} \geq 0$ and $h_{2} \geq 0$ and $h_{3} \geq 0$

$H_{1}: h_{0}<0$ or $h_{1}<0$ or $h_{2}<0$ or $h_{3}<0$

In order to contrast these hypotheses, the so called Wald Test is applied:

$$
(S \tilde{\gamma}-S \hat{\gamma})^{\prime}\left[S \operatorname{cov}(\hat{\gamma}) S^{\prime}\right]^{-1}(S \tilde{\gamma}-S \hat{\gamma})
$$

Where $\hat{\gamma}$ is a consistent estimator of $\gamma, S$ represents a matrix that summarizes the imposed restrictions for the defined inequalities, and $\tilde{\gamma}$ is the vector that minimizes the expression [2] below $H_{0}$.

In equation [1] we test complementarity in the intensity of innovation. Nevertheless, considering that not all firms that comprise our sample innovate, and also that the effect of the obstacles on the intention to innovate may be different, we are interested in testing complementarity in the probability of innovating. For this purpose, we define a probit model:

$$
P I_{i}=\sum_{l=0}^{2^{k}-1} \lambda_{l} s_{i l}+\sum_{j=1}^{p} \omega X_{i j}+v_{i}
$$


Where $P I_{i}$ is the latent variable corresponding to the probability to innovating, while $X_{i j}$ and $s_{i l}$ are control and states of obstacles perception variables respectively, defined above. $P I_{i}$ assumes positive values for innovating firms and negative values for those that do not innovate. In this case, the constraints and hypothesis test for complementarity is analogous in for the intensity of innovation, but the $\gamma_{l}$ 's are replaced by the corresponding $\lambda_{l}$ 's.

As mentioned earlier, modularity tests are based on consistent estimates of the $\gamma_{l}$ (in the case of innovation intensity) and $\lambda_{l}$ (in the case of propensity to innovation). In this regard, an important issue is that we can observe a firm's innovation activity only if this firm actually innovates, then we have left-censored observations on the firm's innovation performance. Additionally, by the way in which the intensity innovation indicator was constructed, it is right-censored. This is a potentially significant issue (Mohnen and Röller, 2005), thus, we performed maximum likelihood estimation of a generalized Tobit to obtain consistent estimates of the parameters in [1] and [3] (Amemiya, 1973). To carry out these regressions, $\varepsilon_{i}$ and $v_{i}$ are assumed to be normally distributed with mean zero and variance-covariance matrix $\Sigma$. While it could be used generalized nonlinear models (i.e. Poisson or negative binomial) to model the innovation, the variation in innovation due to the presence of different obstacles combinations would not be so obvious as represented by the system of inequalities underlying to the hypothesis of complementarity (supplementary), as it is needed.

\subsection{Data Source and Indicators}

We used a primary data source based on a technological survey ${ }^{8}$ done over 2011 to 257 software and related services producer firms from Argentina, covering the period 2008-2010. The survey asks about the general structural aspects of the firms (size, origin of capital, exports, sales, employment, type of production, etc.); their demand structure and product destination; external linkages and relationships with different types of actors and objectives (technical assistance, quality management, joint venture, finance or R\&D); innovative activities (types of innovations introduced, degree of novelty, etc.); capabilities (organization of the work process, quality management, training structure, etc.); appropriability issues and the impact of public policies. Data were used to construct a series of indicators to run the pertinent regressions required to test the supermodularity and submodularity between obstacles.

As dependent variables we use two indicators of Innovation, one for each stage of the innovation process. For testing complementarities between obstacles on the propensity to innovate, a dummy indicator (Innovation) was calculated, assuming 1 if the firm introduced a new product or service in the period considered, or 0 otherwise. Regarding the test of complementarities on the intensity of innovation a continuous variable was calculated (Intensity of Innovation), summing if the firm introduced new products, new processes, improved products, significant improved processes, organizational changes, or developed new commercial channels; all weighted according to the novelty degree of the innovation: assuming 1 if the innovation was new only for the firm, and 3 if the innovation was new also for the market. Following the descriptive statistics of innovation in the sample, we can see that $64 \%$ of the sample firms innovate and std. dev. 4.72, as for the intensity of innovation the observed mean is 7.13 and std. dev. 0.48 , while the median is $7.00^{9}$.

\footnotetext{
8 "Capacity of Absorption and Production Systems Connectivity and Local Innovation". Carolina Foundation (id. 386317).

${ }^{9}$ Propensity assumes values between 0 and 18 .
} 
As independent variables, a series of obstacles to innovation indicators were constructed. Four obstacles were taken into account, aiming to cover the different categories of obstacles, with the available data. To examine financial and risk obstacles to innovation we selected the obstacle "lack of appropriate sources of finance" (obstacle 1), and to examine internal knowledge-skills obstacles we selected the obstacle "lack of skilled personnel" (obstacle 2), two very common obstacles used in previous empirical works of this kind. To examine appropriability obstacles we chose the obstacle of danger of copy of innovations by competitors, labeled "weakness of appropriability" (obstacle 3); and finally, to examine external knowledge-skills obstacles to innovation we selected the obstacle "lack of innovation opportunities due to demand" (obstacle 4), which more precisely represents the situation in which demand does not adequately appreciate the innovations, thus, there is a certain lack of technological or innovation opportunities in the market. In order to derive the inequality constraint underlying the supermodularity innovation function definition, consider $K$ obstacles to innovation, which are assumed to be binary: 1 (high) or 0 (low). $16 C_{j}$ dummy indicators of obstacles to innovation were constructed, representing the presence of these 4 types of obstacles. We define $C_{j}$ as a string of $K$ binary digits, which represent each obstacle. Considering all possible combinations and ordering under "max" operation we obtain a set $\mathrm{C}$ with $2^{\mathrm{K}}$ elements, in this case we have chosen four obstacles $(K=4)$, so the elements in $\mathrm{C}$ are: (0000: Adopts 1 if the firm does not face the obstacles to innovation considered), (0001: Adopts 1 if the firm face only the obstacle 4) ... (1111: Adopts all the obstacles to innovation considered). The importance of obstacles was answered on a Lickert scale in the survey. To convert to dummy variables, we consider the average value of each variable as a cutoff point, so that if the response of a particular firm is less than the average it takes the value 0 , otherwise 1. Averages are 3.37 for obstacle 1, 4.05 for obstacle 2, 2.42 for obstacle 3, and 2.20 for obstacle 4 . Based on the above specifications, we only need to carry out pair-wise comparisons and thus, using the supermodularity definition, we can determine $\left(\begin{array}{l}K \\ 2\end{array}\right)$ comparisons with $2^{\mathrm{K}-2}$ nontrivial inequalities for each. Particularly, with four obstacles $(K=4)$, the 4 nontrivial inequality restrictions for obstacles 1 and 2 to be complementary in innovation, as defined above, can written as:

$$
I(10 X X, \beta)+I(01 X X, \beta) \leq I(00 X X, \beta)+I(11 X X, \beta)
$$

Where $X X=\{00,01,10,11\}$. The comparisons between other obstacles are analogous; it is only necessary to change the position of arguments of $C_{j}$ into $I(\ldots, \beta)$ according to the position of obstacles to be compared. Complementarity over all obstacles is given, whenever all inequality constraints (24 in our case) are satisfied (Mohnen and Röller, 2005).

In reference to the obstacles considered, $12.3 \%$ of firms established that none of them has an important influence. Lack of appropriate sources of finance and innovation opportunities due to demand were seen as significant by $51,6 \%$ and $50,8 \%$ of the firms respectively, while lack of skilled personnel and weakness of appropriability were identified as important by $38,3 \%$ and $37,9 \%$ of the firms respectively.

Finally, as control, we considered typical structural variables (Size, Origin of Capital and Export Profile) and indicators of the main determinants of innovation (Internal Competences, External Linkages and Innovative Efforts): As structural indicators:

- Size is a continuous indicator considered by the number of employees in 2010;

- Export Profile is another continuous variable that considers the percentage of sales coming from exports in 2010;

- Origin of Capital is a dummy variable, adopting the value 1 if the firm has more than $50 \%$ in foreign capital ownership and 0 otherwise.

As the main determinants of innovation: 
- An ordinal indicator of Internal Competences was calculated taking into account the sum of three ordinal sub indicators: a) qualification of the personnel, based on a ad hoc index: assumes 1 when the index is below 20\%, 2 when the index is between $19 \%$ and $23 \%$, and 3 when the index is between $22 \%$ and $50 \%$; $b$ ) quality certification: assumes 1 when a firm does not certify any norm and does less than 7 kinds of quality activities or when a firm has only a Ticket or SLA certifications and does less than 6 kinds of quality activities; assumes 2 when a firm has CMM or ISO certification or does more than 6 kinds of quality activities besides having quality certifications; assumes 3 when a firm has CMM3 or higher certification or ISO and does more than 8 kinds of quality activities; $c$ ) R\&D structure: assumes 3 when a firm has a formal team for R\&D activities conformed at least by 8 workers or at least by 3 workers when a firm has 30 or less employees; assumes 2 in the other cases when a firm has a formal team, or when a firm has an informal team for R\&D activities at least by 8 workers or at least by 3 workers when a firm has 30 or less employees; assumes 1 when a firm has an informal team, and when a firm does not have a team at all;

- Another ordinal indicator of External Linkages that takes into account the interactions established by a firm with other firms or outside sources for collective R\&D activities, technical and/or quality assistance (assumes 3 if the firm interacts with other agents for the three kinds of interactions, 2 if the firms interacts for two of the three types, and 1 otherwise);

- An ordinal indicator of Innovative Efforts, that takes into account the sum of types of innovative activities (license acquisitions related to new products or processes, package or generic software bought that implied improvements to the firm, external acquisition of specific software for the firm, internal software development specific to the firm, implementation of continuum improvement programs, reverse engineering and adaptation, development of new products or processes, internal $\mathrm{R} \& \mathrm{D}$, external $\mathrm{R} \& \mathrm{D}$, contract of consultancies to product or process innovation, and innovation oriented training) done by the firm: assumes 1 when the firm has done less than 4 types of activities, 2 when the firm has done between 4 and 6 activities, and 3 when the firm has done more than 6 innovative activities.

\section{EMPIRICAL FINDINGS AND IMPLICATIONS}

\subsection{Propensity to Innovate and the Intensity of Innovation}

Table 1 shows the maximum likelihood estimates of the models, both the propensity to innovate model (Probit) and the intensity of innovation model (Tobit). Both models show goodness of fit: the propensity of innovation model predicts around $68 \%$ of the cases and the correlation of predicted and observed observations of the intensity of innovation model is 0.54 .

\section{$\langle$ Table 1>}

Also, we can see that all the coefficient signs of the basic determinants of innovation are the expected ones: a positive relation between innovation and internal competences, innovative efforts and external linkages. However, the coefficients are statistically significant only related to the intensity of innovation. Both models show an inverse and statistically significant relation between foreign origin of capital and innovation. That is, the national firms have both 
a higher probability to become innovators, than to increase its innovation level, in respect to foreign firms. A significant, but very small, positive coefficient was found between size and the intensity of innovation. The sign and statistical significance of the coefficient of the obstacle indicators have no economic interpretation, and serve basically as a first step to perform the complementarity and substitutability tests that we present in next section.

\subsection{The complementarity and substitutability between obstacles to innovation}

First, we concentrate in the relations between obstacles to become an innovator. In that sense, the tests related to the propensity to innovate are presented below in Table 2 . There are the Wald statistics of each pair of obstacles, both for complementarity test (supermodularity) and substitutability tests (submodularity). Each test is accepted at $10 \%$ of significance if the statistic is below 1,642 and is rejected if is above 7,094 (Kodde and Palm, 1986).

\section{<Table 2>}

Related to the propensity to innovate, the supermodularity and submodularity test found complementarity between obstacle 2 and 3, rejecting also substitutability between these obstacles, and complementarity between obstacles 1 and 2, and between obstacles 1 and 4 . Regarding the submodularity tests, substitutability was found between obstacles 1 and 3, between obstacle 2 and 4 that also rejects complementarity, and finally, between obstacle 3 and 4.

Regarding the intensity of innovation, as Table 3 shows, the supermodularity and submodularity tests found complementarity and rejects susbstitutability between obstacles 1 and 2; and 2 and 3. Between obstacle 1 and 4, the tests only found complementarity. On the other hand, substitutability was found between obstacle 2 and 4, and between obstacle 3 and 4.

\section{<Table 3>}

\subsection{Implications for policy makers}

The relations found in 4.2 have particular policy implications. On the one hand, when two obstacles are complementary, policies to remove them are supplementary. In this case, actions focused in only one of them, diminish the constraining effect of the other. On the other hand, by contrary, when the obstacles are substitutes, the policies are complementary and it is convenient that the policy actions address it jointly. When the relations found are considered as a whole, it allow to compare the potential benefits of alternative policy packages, and to take into account the feedback effects between the joint attack of diverse barriers to innovation.

Figures 1 and 2 illustrate as a whole the existence of relations of complementarity and substitutability found in the previous section between policies in two stages of the innovation process of firms: first, to become an innovator and, secondly, to increase the intensity of the innovation. An additional issue relevant to policy makers is if it necessary, either convenient, to design specific policy instruments to different stages of the innovation process. That is, if should be designed different policy packages according the objective to create innovators, or according the objective to increase the innovativeness in already innovator firms.

\section{<Figure 1>}


It can be seen that in both stages of the innovation process three pairs of obstacles restrict innovation in a complementary way (lack of appropriate sources of finance and lack of skilled personnel; lack of appropriate sources of finance and lack of innovation opportunities due to demand; and lack of skilled personnel and weakness of appropriability), and two pairs of obstacles acts over innovation as substitutes (lack of skilled personnel and lack of innovation opportunities due to demand; and between weakness of appropriability and lack of innovation opportunities due to demand).

\section{<Figure 2>}

Our findings show small discrepancies in the two stages of the innovation process. The main difference is that the obstacles lack of appropriate sources of finance and weakness of appropriability are substitutes over the propensity to innovate and not for the intensity of innovation. These results differ from those obtained in previous studies (Mohnen and Röller, 2005; Strube and Resende, 2009), in which the differences between the two stages are more important. This suggests that could arise specific differences related to KIBS sectors in emerging economies related to this issue, and that is the main contribution to the literature. In addition, for policy makers, our results point out that in the particular case of the Argentinean software sector, policy innovation actions aimed to create innovators are also useful to increase the level of innovation of firms that have already introduced innovations.

Aside the analysis presented, it should be recognized that it do not allow the identification of such thing as a set of "optimal" actions, nor determine a superior or necessarily more efficient policy package respect to the others. Instead, the results of the presented analysis can serve as justification for alternative policy packages. Ultimately, the innovation policy making must take into account not only the existence of the complementarity and substitutability relations between policies, but also other related aspects as, for example, the relative importance of each obstacle, the viability or feasibility to design a policy in order to attack a determined objective, the financial and non-financial costs of the policy, and the time needed in order for the policy to take effect.

\section{CONCLUSIONS}

The available empirical literature that applies the methodology developed by Mohnen and Röller (2005) to evaluate the existence of relations of complementarity or supplementarity between distinct innovation policies is scarce and has been focused on manufacturing sectors in developed countries. In this sense, the paper advances in the application of that methodology to a KIBS sector in an emerging economy.

The paper also contributes with practical implications to the innovation policy making in the software sector in Argentina arising from the complementarities found between obstacles. The existence of supplementarity relations between obstacles suggests the ease of attacking them simultaneously. Instead, when the obstacles are complementary, it appears more convenient to attack only one of them; thus, in the case that the obstacle is neutralized, the obstacle that remains loses importance.

Contrary to the existing previous studies in manufacturing sectors, our main finding show that in the Argentinean software sector the relations between complementarity and substitutability in obstacles to innovation tend to be very similar, regardless if the firm is in the stage of turning non-innovative firms into innovators, or if in the stage of increasing (or decreasing) the intensify of its innovation activity. This reinforces the idea that KIBS has proper 
particularities on innovation issues and, in that sense, which requires a specific sectoral policy.

\section{Acknowledgements}

The authors are extremely grateful for all the careful suggestions and enriching comments received from two anonymous referees of the journal and from the editors, and especially from Dr. Gustavo Crespi to early versions of this manuscript. The authors gratefully acknowledge financial support in data collection to Carolina Foundation (Spain), and Science and Technological Secretary (Secyt) from Universidad Nacional de Córdoba (UNC, Argentina). The findings and conclusions of the paper are the sole responsibility of the authors.

\section{References}

AMEMIYA, T. 1973. Regression analysis when the dependent variable is truncated normal. Econometrica, 41, 997-1016.

ANCHORDOGUY, M. 2000. Japan's software industry: a failure of institutions? Research Policy, 29, 391-408.

ARORA, A., ARUNACHALAM, V. S., ASUNDI, J. \& FERNANDES, R. 2001. The Indian software services industry. Research Policy, 30, 1267-1287.

ATHREYE, S. S. 2005. The Indian software industry and its evolving service capability. Industrial and Corporate Change, 14, 393-418.

BARLETTA, F., PEREIRA, M., ROBERT, V. \& YOGUEL, G. 2013. Argentina: Dinámica reciente del sector de software y servicios informáticos. Revista de la CEPAL, 110, 137-155.

BREZNITZ, D. 2007. Industrial R \& D as a national policy: Horizontal technology policies and industry-state co-evolution in the growth of the Israeli software industry. Research Policy, 36, 1465-1482.

CASSIMAN, B. \& VEUGELERS, R. 2006. In Search of Complementarity in Innovation Strategy: Internal R\&D and External Knowledge Acquisition. Management Science, 52, 6882.

CHUDNOVSKY, D. \& LÓPEZ, A. 2005. The software and information services sector in Argentina: The pros and cons of an inward-oriented development strategy. Information Technology for Development, 11, 59-75.

D'ESTE, P., IAMMARINO, S., SAVONA, M. \& VON TUNZELMANN, N. 2012. What hampers innovation? Revealed barriers versus deterring barriers. Research Policy, 41, 482488.

DJELLAL, F. \& GALLOUJ, F. 2001. Patterns of innovation organisation in service firms: postal survey results and theoretical models. Science and Public Policy, 28, 57-67.

DREJER 2004. Identifying innovation in surveys of services:a Schumpeterian perspective. Research Policy, 33, 551-562.

GALIA, F. \& LEGROS, D. 2004. Complementarities between obstacles to innovation: evidence from France. Research Policy, 33, 1185-1199.

GALLOUJ, F. \& SAVONA, M. 2009. Innovation in services: a review of the debate and a research agenda. Journal of evolutionary economics, 19, 149-172.

GALLOUJ, F. \& WEINSTEIN, O. 1997. Innovation in services. Research Policy, 26, 537556.

HAJELA, A. \& AKBAR, M. 2013. Internationalisation of small and medium software firms from India. International Journal of Technological Learning, Innovation and Development, 6, 88-101.

HOU, J. \& MOHNEN, P. 2011. Complementarity between internal knowledge creation and external knowledge sourcing: evidence from Chinese manufacturing firms. UNU-MERIT WP Series. 
IAMMARINO, S., SANNA-RANDACCIO, F. \& SAVONNA, M. 2009. The perception of obstacles to innovation. Foreign multinationals and domestic firms in Italy. Revue d'économie industrielle, 75-104.

KODDE, D. A. \& PALM, F. C. 1986. Wald criteria for jointly testing equality and inequality restrictions. Econometrica: journal of the Econometric Society, 1243-1248.

LOKSHIN, B., BELDERBOS, R. \& CARREE, M. 2008. The Productivity Effects of Internal and External R\&D: Evidence from a Dynamic Panel Data Model. Oxford Bulletin of Economics and Statistics, 70, 399-413.

MADRID-GUIJARRO, A., GARCIA, D. \& VAN AUKEN, H. 2009. Barriers to Innovation among Spanish Manufacturing SMEs. Journal of Small Business Management, 47, 465-488.

MALERBA, F. \& NELSON, R. R. 2011. Learning and catching up in different sectoral systems: evidence from six industries. Industrial and Corporate Change, 20, 1645-1675.

MANCUSI, M. L. \& VEZZULLI, A. 2010. R\&D, Innovation and Liquidity Constraints. Milano, Italy: KITeS, WP 30/2010. Universita'Bocconi. .

MILES, I. 2004. Innovation in services. In: FAGERBERG, J., MOWERY, D. C. \& NELSON, R. R. (eds.) The Oxford handbook of innovation. Oxford University Press.

MILES, I. 2005. Knowledge intensive business services: prospects and policies. Foresight, 7, 39-63.

MILES, I., KASTRINOS, N., FLANAGAN, K., BILDERBEEK, R. \& DEN HERTOG, P. 1995. Knowledge-intensive business services. Users, carriers and sources of innovation, Manchester, PREST.

MILGROM, P. \& ROBERTS, J. 1990. The Economics of Modern Manufacturing: Technology, Strategy, and Organization. American Economic Review, 80, 511-528.

MIRAVETE, E. J. \& PERNIAS, J. C. 2006. Innovation complementarity and scale of production. Journal of Industrial Economics, 54, 1-29.

MOHNEN, P. \& RÖLLER, L.-H. 2005. Complementarities in innovation policy. European Economic Review, 49, 1431-1450.

MOWERY, D. C. \& LANGLOIS, R. N. 1996. Spinning off and spinning on(?): the federal government role in the development of the US computer software industry. Research Policy, 25, 947-966.

MULLER, E. \& DOLOREUX, D. 2009. What we should know about knowledge-intensive business services (KIBS). Technology in Society, 31, 64-72.

NIOSI, J., ATHREYE, S. \& TSCHANG, T. 2012. The global computer software sector. Economic Development As a Learning Process: Variation Across Sectoral Systems.

OPSSI 2013. Reporte semestral sobre el Sector de Software y Servicios Informáticos de la República Argentina. Buenos Aires: Observatorio Permanente de la Industria del Software y Servicios Informáticos de la República, CESSI.

RIZK, N. 2012. Free and open source software (FOSS) as a vehicle for human development in Egypt: Some evidence and insights. International Journal of Technological Learning, Innovation and Development, 5, 221-236.

SAVIGNAC, F. 2008. Impact of financial constraints on innovation: What can be learned from a direct measure? Economics of Innovation and New Technology, 17, 553-569.

STRUBE, E. \& RESENDE, M. 2009. Complementarity of innovation policies in the Brazilian industry: an econometric study. CESifo working paper, 2780.

TETHER, B. \& SWAN, G. 2003. Services, Innovations and the Science Base: An Investigation into the UK's 'System of Innovation' using evidence from the UK's third community innovation survey. International workshop: Innovation in Europe. Rome.

TOPKIS, D. M. 1998. Supermodularity and complementarity, Princeton Univ Pr.

TOURIGNY, D. \& LE, C. D. 2004. Impediments to innovation faced by Canadian manufacturing firms. Economics of Innovation and New Technology, 13, 217-250. 
URIONA, M., MORERO, H. A. \& BORRASTERO, C. 2013. 'Catching up' en servicios intensivos en conocimiento: el caso de la producción de software y servicios informáticos de Argentina y Brasil. Revista Iberoamericana de Ciencia, Tecnología y Sociedad, 8, 117-146. 
Table 1 - Maximum likelihood estimates of the models

Variables

Propensity to Innovate

Intensity of Innovation

Coefficient $\left({ }^{1}\right)$

Sign. $\left({ }^{2}\right)$

Coefficient $\left({ }^{1}\right) \quad$ Sign. $\left({ }^{2}\right)$

Controls

Size

Export Profile

Origin of Capital

Internal Competences

Innovative Efforts

External Linkages

States

0000

0001

0010

0011

0100

0101

0110

0111

1000

1001

1010

1011

1100

1101

1110

1111

Log-likelihood

Wald-statistic

P-Value

Perc. of Correct Predictions

Sq. Corr (obs. and pred.)

( $\left.{ }^{1}\right)$ St.err. in parentheses

$\left(^{2}\right) * * *$ Significant at $1 \%$;

** Significant at 5\%;

$-229,9$

224,5

$2,22 \mathrm{E}-16$

0,68

$0,0054(0.0028)$

$-0,3005 \quad(0.0092)$

$-0,0017 \quad(0.0135)$

$-1,9767$ (1.1803)

$-0,3107 \quad(0.1754)$

$1,6384 \quad(0.4265)$

$0,0427 \quad(0.0608)$

$1,5715 \quad(0.3420)$

$0,0796 \quad(0.0535)$

$0,6257 \quad(0.3712)$

$0,2625 \quad(0.1593)$

$-1,5839$ (1.1342)

$0,4585 \quad(0.1879)$

$-0,8216 \quad(1.3452)$

$0,4144 \quad(0.2253) \quad * \quad 0,2184 \quad(1.6015)$

$0,1816 \quad(0.1879)$

$-2,4931(1.2911)$

$0,2725 \quad(0.2157)$

$-0,7670 \quad(1.5253)$

$-0,4612 \quad(0.2367)$

$-3,7593$ (1.4688)

$0,6080 \quad(0.2898)$

$-2,4279$ (2.0908)

$0,3397 \quad(0.3017)$

$-1,1699$ (2.1527)

$0,2169 \quad(0.2022)$

$-0,5703 \quad(1.4412)$

$0,3928 \quad(0.1765)$

$-0,3897 \quad(1,2651)$

$-0,0089 \quad(0.2382)$

$-3,8512 \quad(1,5621)$

$0,2987 \quad(0.1949)$

$-1,2399$ (1.3797)

$0,2549 \quad(0.1794)$

$-1,1873$ (1.2751)

$0,3476 \quad(0.2162)$

$-0,4856 \quad(1.5635)$

$0,3998 \quad(0.2529)$

$1,7400 \quad(1.8155)$

$0,3060 \quad(0.2080)$

0,5398 (1.4807)

$-667,0$

726,8

2,22E-16

0,54

$* * *$

$* * *$

$*$

Table 2 - Complementarity and Substitutability Tests. Propensity to Innovate

\begin{tabular}{|c|c|c|c|c|c|c|}
\hline Pair of Obstacles & $1-2$ & $1-3$ & $1-4$ & $2-3$ & $2-4$ & $3-4$ \\
\hline Supermodularity Test & 0,132 & 4,626 & 0,004 & 0,001 & 7,282 & 2,540 \\
\hline Submodularity Test & 5,581 & 0,310 & 6,494 & 7,286 & 0,001 & 0,879 \\
\hline
\end{tabular}


Table 3 - Complementarity and Substitutability Tests. Intensity of Innovation

\begin{tabular}{lcccccc}
\hline \multicolumn{1}{c}{ Pair of Obstacles } & $1-2$ & $1-3$ & $1-4$ & $2-3$ & $2-4$ & $3-4$ \\
\hline Supermodularity Test & 0,349 & 4,100 & 0,532 & 1,308 & 3,984 & 3,833 \\
Submodularity Test & 7,273 & 2,196 & 5,923 & 7,563 & 1,395 & 1,504
\end{tabular}

Obstacle definitions: $1=$ lack of appropriate sources of finance; $2=$ lack of skilled personnel; $3=$ weakness of appropriability; $4=$ lack of innovation opportunities due to demand.

Figure 1 - Complementarity and Substitutability between Policy Actions to Create Innovators

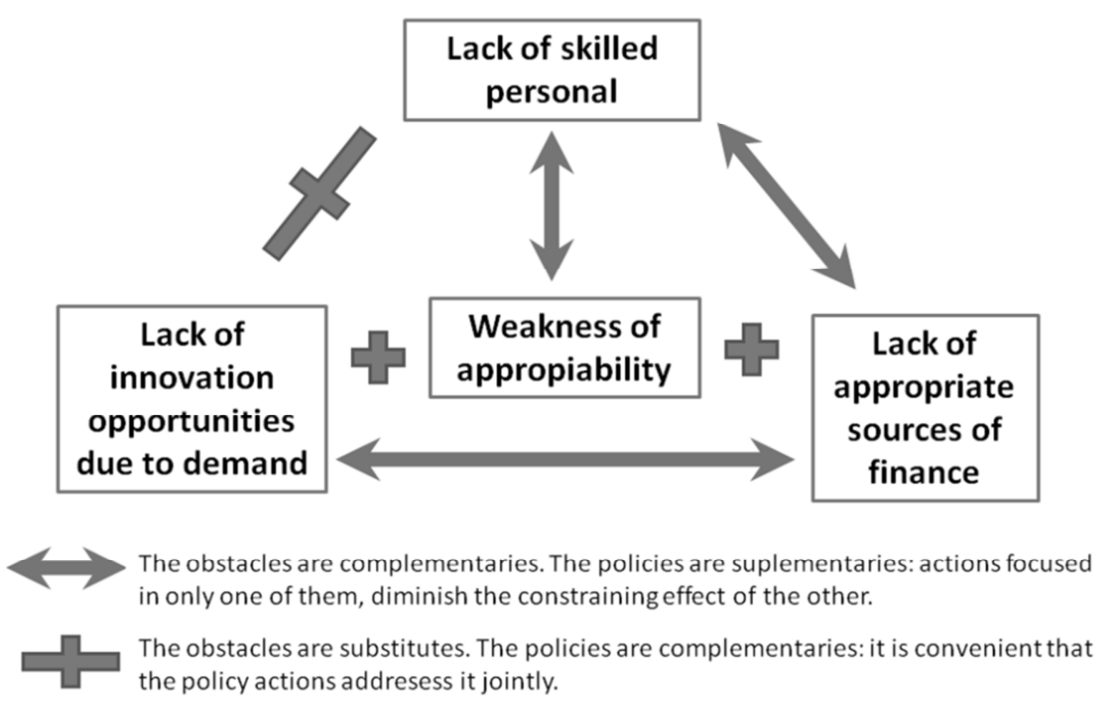

Figure 2 - Complementarity and Substitutability between Policy Actions to Increase Innovation

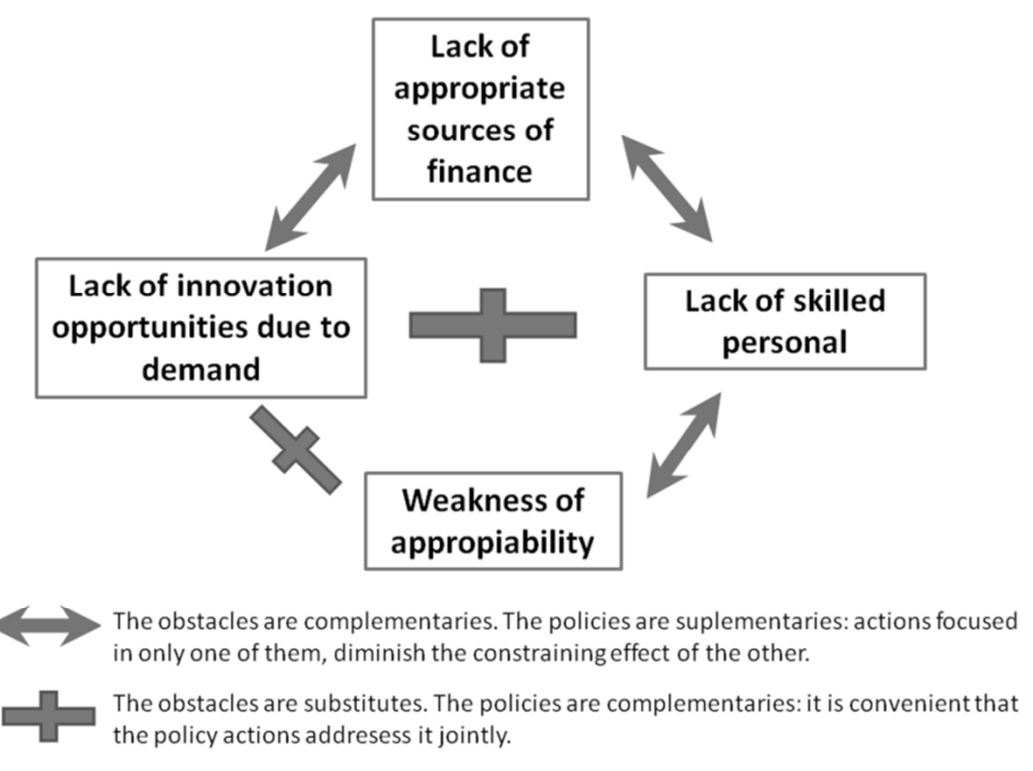

